\title{
PREFERENSI MAHASISWA TERHADAP PENCAHAYAAN BUATAN IDEAL UNTUK RUANGAN KELAS STUDIO GAMBAR
}

\author{
Leonardo \\ (Email: lenard.lee7102neu@gmail.com) \\ Program Studi Desain Interior \\ Fakultas Seni Rupa dan Desain \\ Universitas Kristen Maranatha \\ Jl. Prof. Drg. Surya Sumantri No 65, Bandung, Indonesia
}

\begin{abstract}
ABSTRAK
Studio gambar esensial bagi mahasiswa desain karena digunakan intensif dan dalam waktu lama. Pencahayaan studio gambar yang tepat penting untuk mendukung kinerja menggambar mereka. Oleh karena itu preferensi mahasiswa pada pencahayaan ideal studio gambar dijadikan tujuan penelitian ini. Preferensi mahasiswa dapat dilihat dengan Conjoint Analysis untuk menelaah sejumlah variabel sekaligus pada fenomena yang diangkat dengan cara mendesain profil. Delapan profil pencahayaan ideal studio gambar yang didesain mengandung tujuh atribut yang masing-masing berlevel dua, ditampilkan berupa gambar render suasana interior studio kepada 145 mahasiswa desain interior aktif yang tengah mengambil studio desain di semester yang sama. Dalam profil pencahayaan yang paling diminati ditemukan tiga atribut terpenting secara berurutan yaitu, distribusi pencahayaan (27.3\%), tingkat terang secara menyeluruh (18.2\%), dan tingkat terang pada meja kerja (13.7\%). Penelitian ini menyimpulkan bahwa ketiganya dinilai paling mempengaruhi pencahayaan studio gambar pada kinerja mahasiswa, dan atribut lainnya sebagai nilai tambah jika tiga atribut utama tadi sudah terpenuhi.
\end{abstract}

Kata kunci: kinerja mahasiswa, pencahayaan studio gambar, preferensi mahasiswa, profil pencahayaan ideal studio gambar

\begin{abstract}
Drawing studio is essential for design students because it is used intensively and in a prolonged time. Lighting for drawing studio can support students drawing performance when installed properly. Hence, students' preference for ideal lighting for drawing studios is aimed at this study. Conjoint analysis is used to look into students' preferences through a set of designed profiles. Eight profiles for lighting studios are designed to consist of seven attributes with two levels each, resulting in rendered images by computer and then are exposed to 145 active students of design interior from the ongoing semester. The finding shows three main attributes, lighting distribution (27.3\%), overall lighting intensity (18.2\%), and desk-level lighting intensity (13.7\%) are preferred the most consecutively. This study concludes those three main attributes as the most influential for lighting studio to support students drawing performance, while the rest are considered added value when the main three attributes are already fulfilled.
\end{abstract}

Keywords: ideal lighting profile for drawing studio; lighting for drawing studio; students' performance; students' preference 


\section{PENDAHULUAN}

Studio gambar institusi pendidikan tinggi desain merupakan salah satu fasilitas esensial yang hingga kini tak tergantikan dan disediakan bagi mahasiswa untuk mengerjakan tugasnya dalam konteks belajar yang didominasi oleh kegiatan menggambar. Studio gambar memiliki keunikannya tersendiri dibandingkan ruangan kuliah lainnya, yang terdefinisikan melalui ciri-cirinya yaitu (1) didominasi kegiatan menggambar oleh mahasiswa, yang (2) seringkali menuntut waktu panjang, serta (3) digunakan dengan frekuensi terbanyak dan lama, dengan kata lain studio gambar digunakan secara intensif oleh mahasiswa.

Dengan pertimbangan tingginya frekuensi penggunaan studio gambar, selayaknya studio harus dapat mewadahi dan mendukung kebutuhan mahasiswa secara optimal dari segi fasilitas fisiknya agar proses dan hasil pembelajaran mendesain mereka tercapai secara positif, terlebih secara akumulatif untuk jangka panjang. Tujuan keberadaan studio gambar dinilai berhasil apabila tepat guna dan tepat sasaran dengan mempertimbangkan kebutuhan mahasiswa sebagai pengguna intensnya, salah satunya adalah kebutuhan pengkondisian pencahayaan yang penting untuk mendukung tujuan studio gambar, dalam hal kinerja penglihatan mahasiswa agar mampu menggambar tanpa kesulitan. Oleh sebab itu, preferensi mahasiswa atas pencahayaan studio perlu dipertimbangkan sebagai pendekatan dalam membangun kriteria desain tata cahaya studio gambar.

Telah banyak penelitian di bidang pencahayaan yang mengungkapkan hubungan sebab akibat secara rinci dan mendalam dengan variabel terbatas, namun kenyataannya ada banyak variabel pengaruh yang berdampak bersamaan pada fenomena lingkungan visual dan nonvisual akibat kondisi pencahayaan. Belum lagi masih terbuka lebar area penelitian yang mengungkapkan kinerja belajar mahasiswa di dalam lingkungan institusi pendidikan tinggi. Penelitian ini bermaksud untuk melihat preferensi pencahayaan ideal menurut persepsi mahasiswa sebagai respondennya sehingga akan memanfaatkan alat riset Conjoint Analysis. 


\section{Kinerja Manusia Dipengaruhi Kondisi Pencahayaan Interior}

Masih banyak ditemukan kondisi pencahayaan yang buruk (Lyons, J.B, 2001 dalam Samani, 2011; PR Boyce, A Wilkins, 2018) di banyak insitusi pendidikan akibat kurangnya perhatian pada pengkondisian pencahayaan, padahal jika ditangani dengan tepat dapat mendukung kinerja belajar dan luarannya (Johnson, L.A, 2011 dalam Samani, 2011). Hal tersebut jelas bertentangan dengan tujuan utama pengkondisian pencahayaan agar manusia dapat melakukan aktivitasnya dengan cepat, mudah, nyaman, dan aman (IESNA Lighting Handbook Vol.9 hal.125), dan tentunya menjadi pemicu luaran yang kontra produktif saat melihat saja kerja mata sudah terbebani agar kemudian dapat melakukan aktivitas belajar (Dora, Purnama Esa, 2012) walaupun mata manusia mampu beradaptasi dengan beragam kondisi lingkungan pencahayaan (Innes, Malcolm, 2012). Dengan demikian dapat dipahami mengapa kinerja manusia pasti dipengaruhi lingkungan pencahayaan karena cahaya masuk melalui sistem visual manusia (Hathaway, Warren E et al, 1992).

\section{Conjoint Analysis}

Paparan di atas memperlihatkan ada banyak faktor berinteraksi bersamaan yang saling mempengaruhi kinerja manusia saat beraktivitas, menghasilkan luaran positif bermanfaat jika diterapkan tepat maupun sebaliknya, maupun memunculkan masalah yang merugikan. Banyaknya faktor yang berinteraksi sekaligus itulah yang menjadikan penelitian ini berfokus pada penggunaan metode Conjoint Analysis untuk mampu melihat besar pengaruh tiap variabel pencahayaaan yang diteliti dengan pendekatan pada preferensi responden.

Conjoint Analysis bermula dari ilmu Ekonometri dan Psikologi yakni teknik statistik bermedia survey yang dapat menangani banyak variabel (multivariant) untuk menilai suatu produk/jasa. Oleh sebab itu, secara khusus digunakan pada penelitian yang bertujuan untuk melihat preferensi pasar secara agregat. Produk/jasa dinamakan sebagai profil/stimuli, merupakan gabungan sejumlah karakter yang disebut atribut/variabel yang tersusun menurut tingkat prioritasnya, dengan rumus dituliskan sebagai berikut: 


$$
\text { Jumlah potensi kombinasi }\left(L^{A}\right)=\left(L_{1} \times A_{1}\right) \times\left(L_{2} \times A_{2}\right) \times\left(L_{n} \times A_{n}\right)
$$

Dengan faktor $L=$ jumlah level, dan $A=$ jumlah atribut (jika jumlah level tiap atribut sama) atau A1 dan seterusnya jika jumlah level dari tiap atribut berbeda.

Penelitian ini mengadaptasi penelitian H.D.Cheung dan T.M.Chung (2008) yang menggunakan tujuh atribut dengan setiap atributnya memiliki dua level. Mereka memakai tujuh atribut untuk menilai preferensi atas pencahayaan alami dalam ruangan keluarga oleh penghuni apartemen. Walaupun penelitian ini menggunakan jumlah atribut dan level yang sama, namun dikhususkan pada pencahayaan buatan, mengambil responden mahasiswa, dan memanfaatkan objek kasus ruangan studio gambar.

Jumlah profil secara teori yang dihasilkan utuh sejumlah $2^{7}=128$ kombinasi, namun jumlah sebanyak itu dapat membingungkan dan melelahkan responden saat memilih, sehingga harus dikurangi agar layak uji dengan rumus orthogonal array sebagai berikut:

Syarat jumlah minimum kombinasi $=($ jumlah Level -1$) \times$ jumlah atribut +1

Oleh karena itu didapatkan hasil sebanyak $((2-1) \times 7)+1=8$ profil.

Tabel 1. Tujuh atribut yang masing-masing memiliki dua level - didesain untuk menilai preferensi mahasiswa atas pencahayaan studio gambar yang ideal

\begin{tabular}{llll}
\hline 1 & Tingkat terang secara umum & Terang $(500 \mathrm{Ix})$ & Redup $($ kurang dari $300 \mathrm{Ix})$ \\
\hline 2 & Tingkat terang pada meja kerja & Terang $(500 \mathrm{Ix})$ & Redup $($ kurang dari $300 \mathrm{Ix})$ \\
\hline 3 & Silau dari sumber lampu & Sering & Jarang \\
\hline 4 & Distribusi cahaya lampu secara umum & Rata & Tidak Rata \\
\hline 5 & Pewarnaan dari lampu secara umum & Hangat & Sejuk \\
\hline 6 & Kontrol pengaturan penerangan & mudah & sulit \\
\hline 7 & Tata letak titik lampu & Langsung/direct & Tidak langsung/indirect \\
\hline
\end{tabular}

Setiap profil yang mewakili kombinasi tujuh atribut dan dua level yang berbeda diolah dengan rendering piranti lunak untuk menggambarkan perbedaan dan keunikan kedelapan profil pencahayaan studio gambar. Hasil visualisasinya tampak sebagai berikut: 
Serat Rupa Journal of Design, January 2020, Vol.4, No.1: 51-66

E-ISSN: 2477-586X, ISSN: 2338-3348 | https://doi.org/10.28932/srjd.v4i1.1965 | Received: 09-10-2019, Accepted: 16-01-2020 Leonardo

Preferensi Mahasiswa Terhadap Pencahayaan Buatan Ideal Untuk Ruangan Kelas Studi Gambar

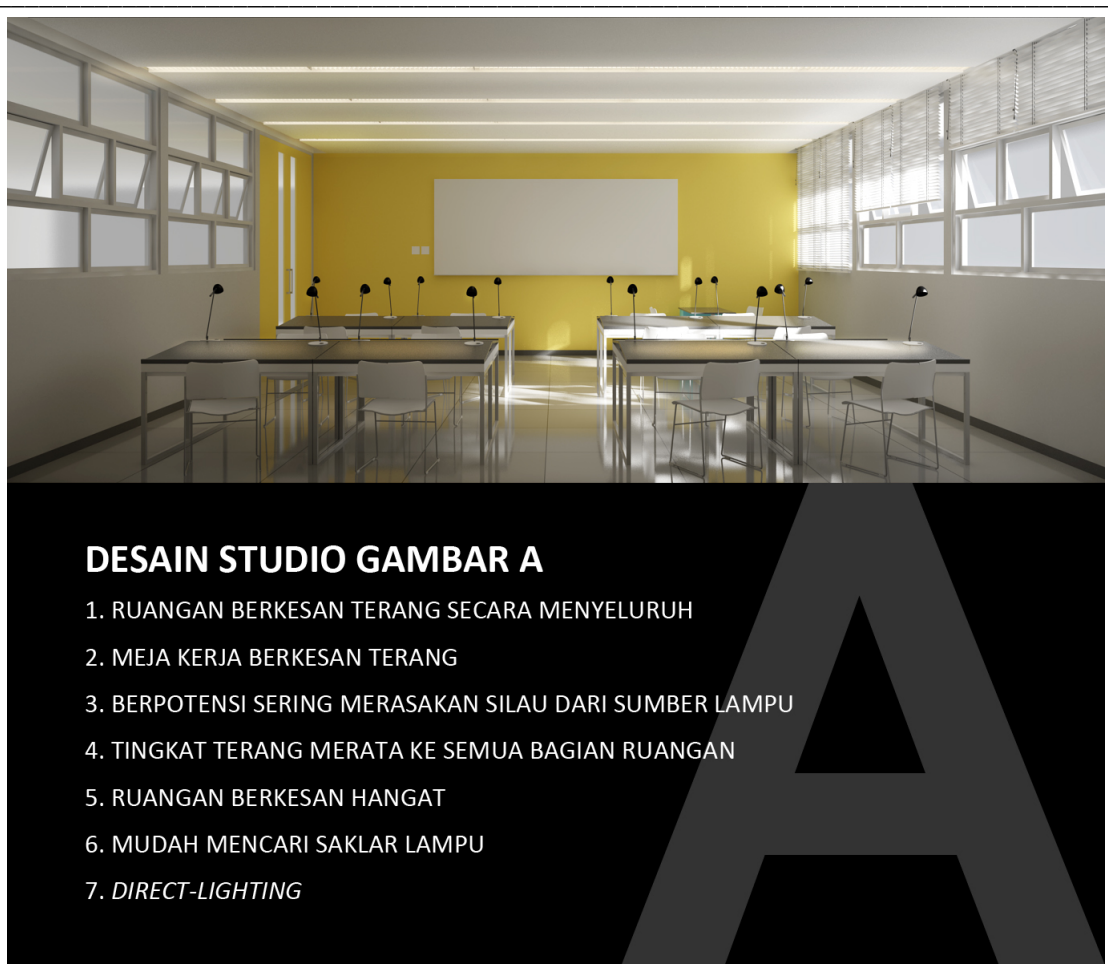

Gambar 1. Visualisasi pencahayaan studio gambar ideal - profil A, yang ditampilkan tercetak kepada responden

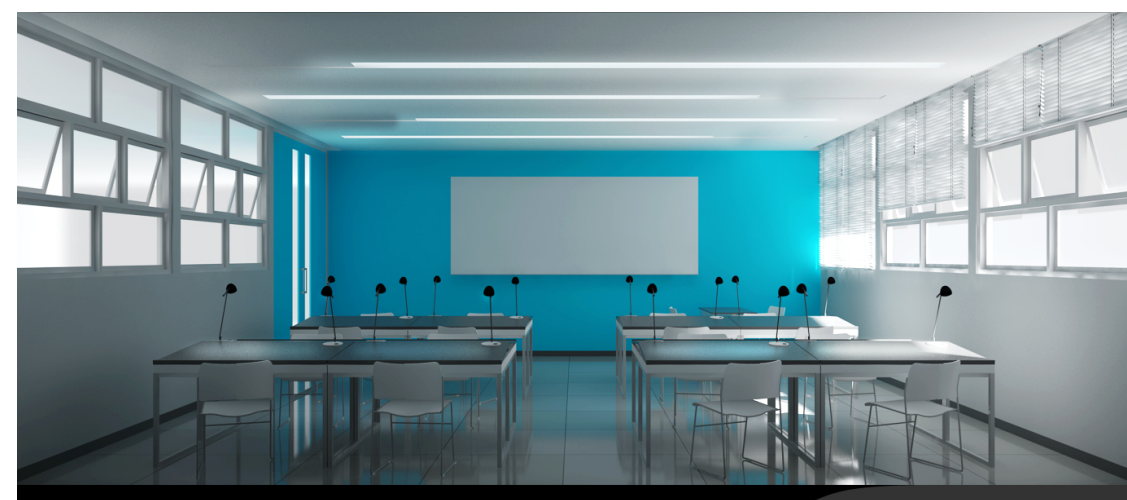

\section{DESAIN STUDIO GAMBAR B}

1. RUANGAN BERKESAN TERANG SECARA MENYELURUH

2. MEJA KERJA BERKESAN TERANG

3. BERPOTENSI MERASAKAN SILAU DARI SUMBER LAMPU

4. TINGKAT TERANG TIDAK MERATA DI SEMUA BAGIAN RUANGAN

5. RUANGAN BERKESAN SEJUK

6. SULIT MENCARI SAKLAR LAMPU

7. INDIRECT-LIGHTING

Gambar 2. Visualisasi pencahayaan studio gambar ideal - profil B, yang ditampilkan tercetak kepada responden 
Serat Rupa Journal of Design, January 2020, Vol.4, No.1: 51-66

E-ISSN: 2477-586X, ISSN: 2338-3348 | https://doi.org/10.28932/srjd.v4i1.1965 | Received: 09-10-2019, Accepted: 16-01-2020 Leonardo

Preferensi Mahasiswa Terhadap Pencahayaan Buatan Ideal Untuk Ruangan Kelas Studi Gambar

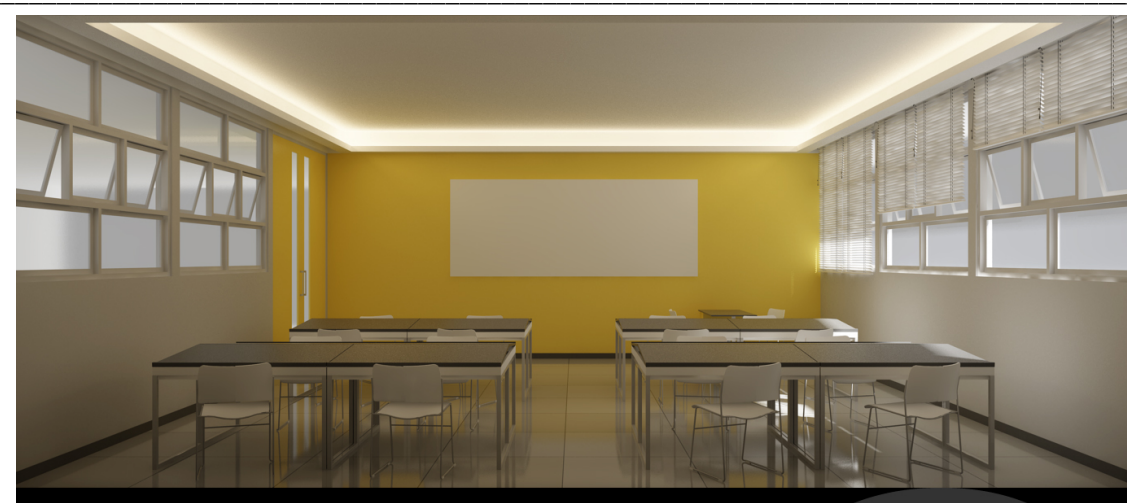

DESAIN STUDIO GAMBAR C

1. RUANGAN BERKESAN TERANG SECARA MENYELURUH

2. MEJA KERJA BERKESAN KURANG TERANG

3. BERPOTENSI KECIL MERASAKAN SILAU DARI SUMBER LAMPU

4. TINGKAT TERANG MERATA DI SEMUA BAGIAN RUANGAN

5. RUANGAN BERKESAN HANGAT

6. SULIT MENCARI SAKLAR LAMPU

7. INDIRECT-LIGHTING

Gambar 3. Visualisasi pencahayaan studio gambar ideal - profil C, yang ditampilkan tercetak kepada responden

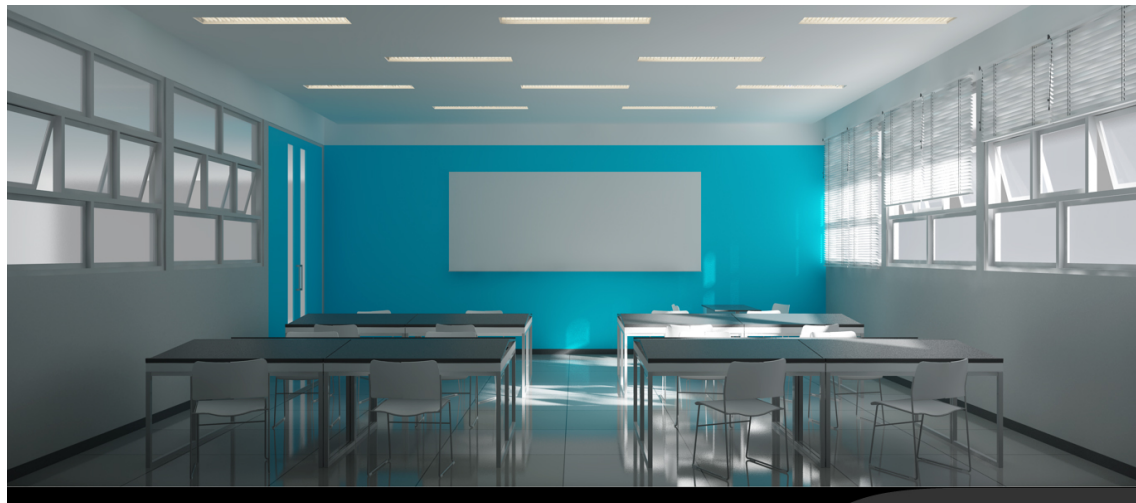

\section{DESAIN STUDIO GAMBAR D}

1. RUANGAN BERKESAN TERANG SECARA MENYELURUH

2. MEJA KERJA BERKESAN KURANG TERANG

3. BERPOTENSI KECIL MERASAKAN SILAU DARI SUMBER LAMPU

4. TINGKAT TERANG TIDAK MERATA DI SEMUA BAGIAN RUANGAN

5. RUANGAN BERKESAN SEJUK

6. MUDAH MENCARI SAKLAR LAMPU

7. DIRECT-LIGHTING

Gambar 4. Visualisasi pencahayaan studio gambar ideal - profil D, yang ditampilkan tercetak kepada responden 


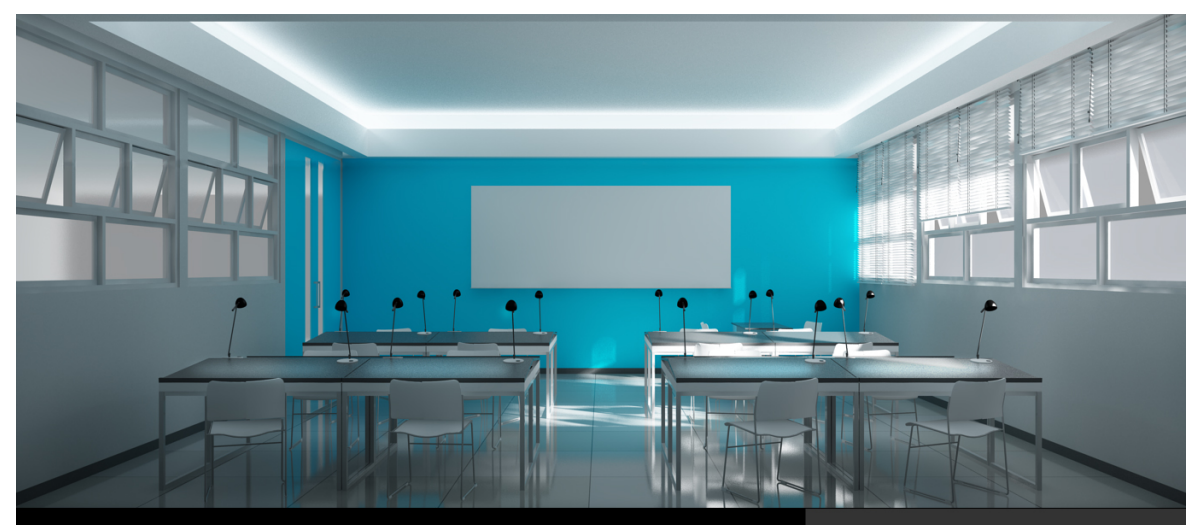

\section{DESAIN STUDIO GAMBAR E}

1. RUANGAN BERKESAN KURANG TERANG SECARA MENYELURUH

2. MEJA KERJA BERKESAN TERANG

3. BERPOTENSI KECIL MERASAKAN SILAU DARI SUMBER LAMPU

4. TINGKAT TERANG MERATA KE SEMUA BAGIAN RUANGAN

5. RUANGAN BERKESAN SEJUK

6. MUDAH MENCARI SAKLAR LAMPU

7. INDIRECT-LIGHTING

Gambar 5. Visualisasi pencahayaan studio gambar ideal - profil E, yang ditampilkan tercetak kepada responden

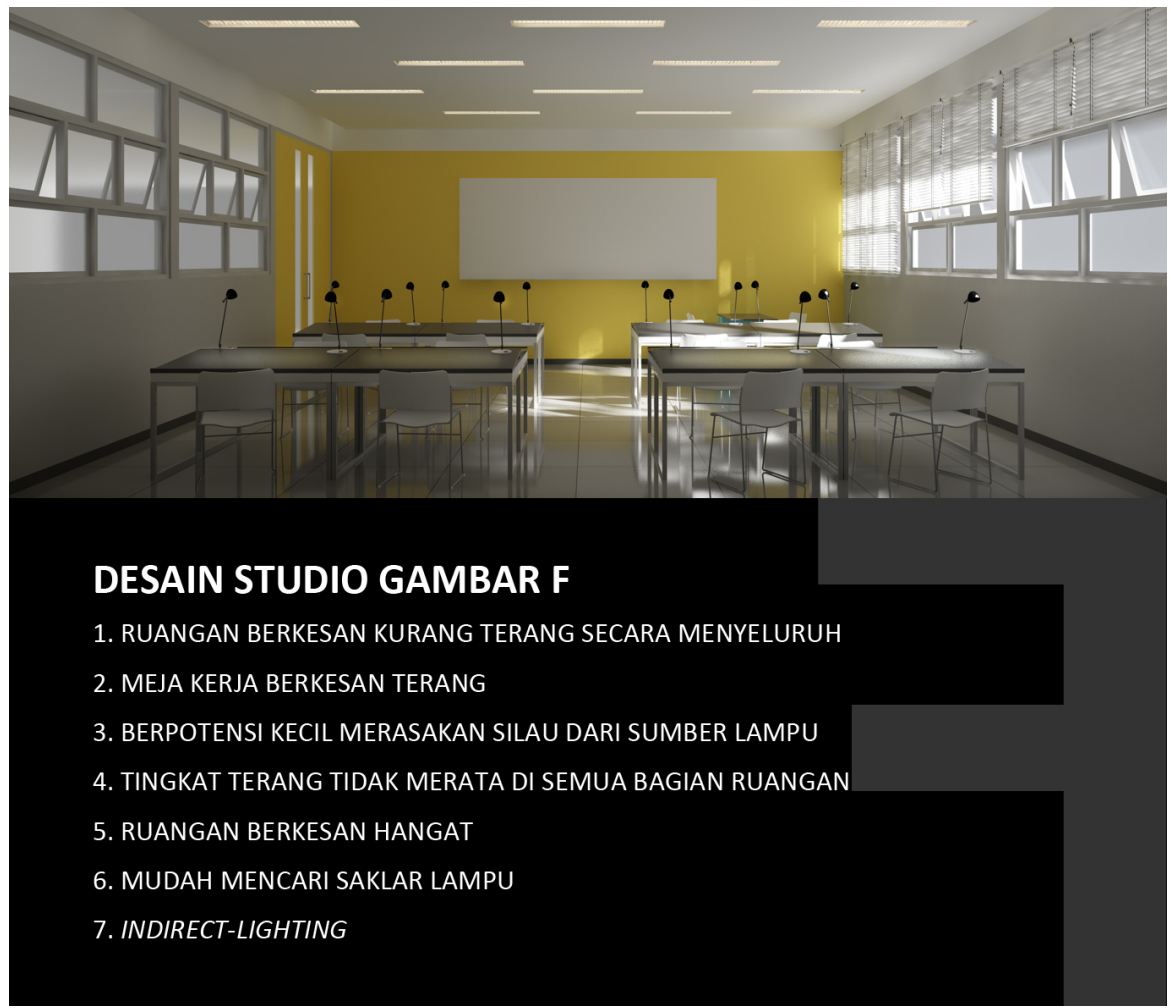

Gambar 6. Visualisasi pencahayaan studio gambar ideal - profil F, yang ditampilkan tercetak kepada responden 


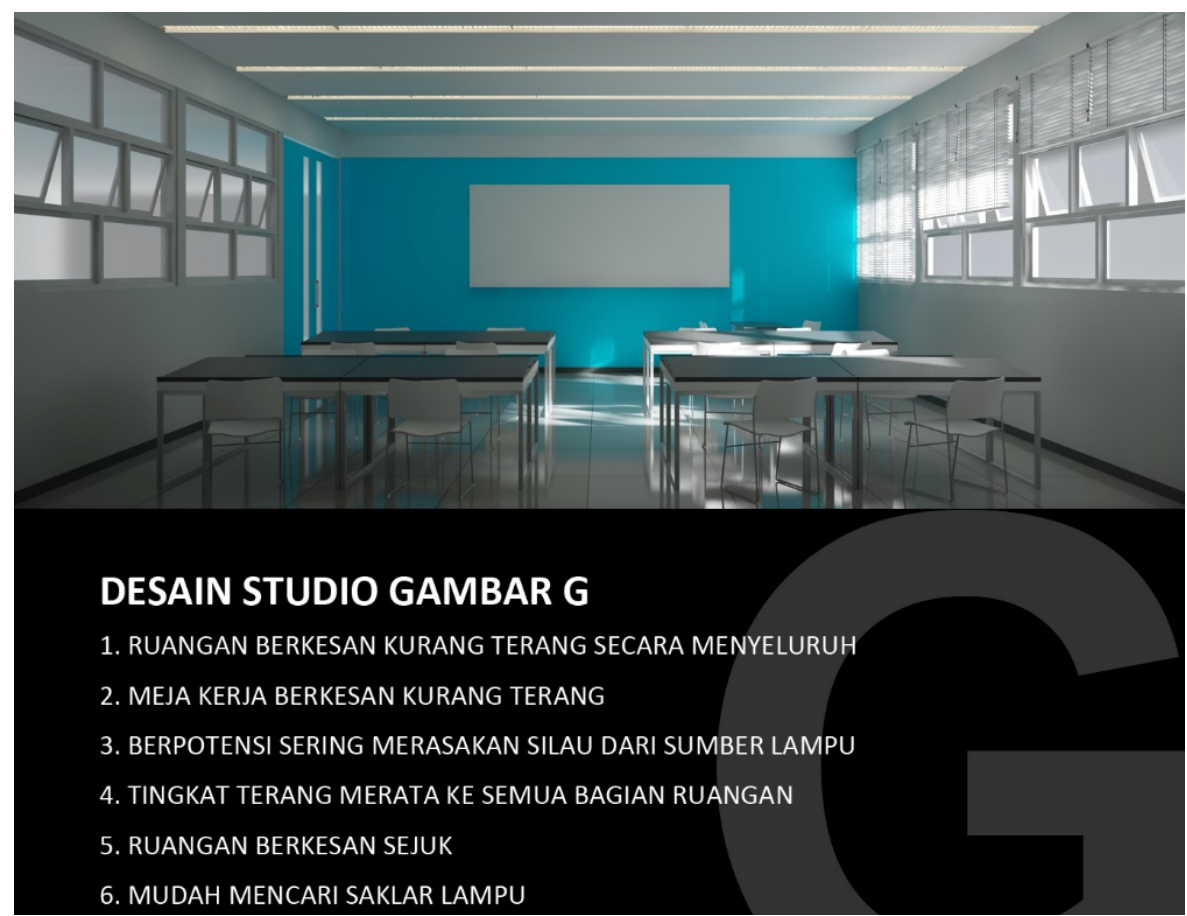

Gambar 7. Visualisasi pencahayaan studio gambar ideal - profil G, yang ditampilkan tercetak kepada responden

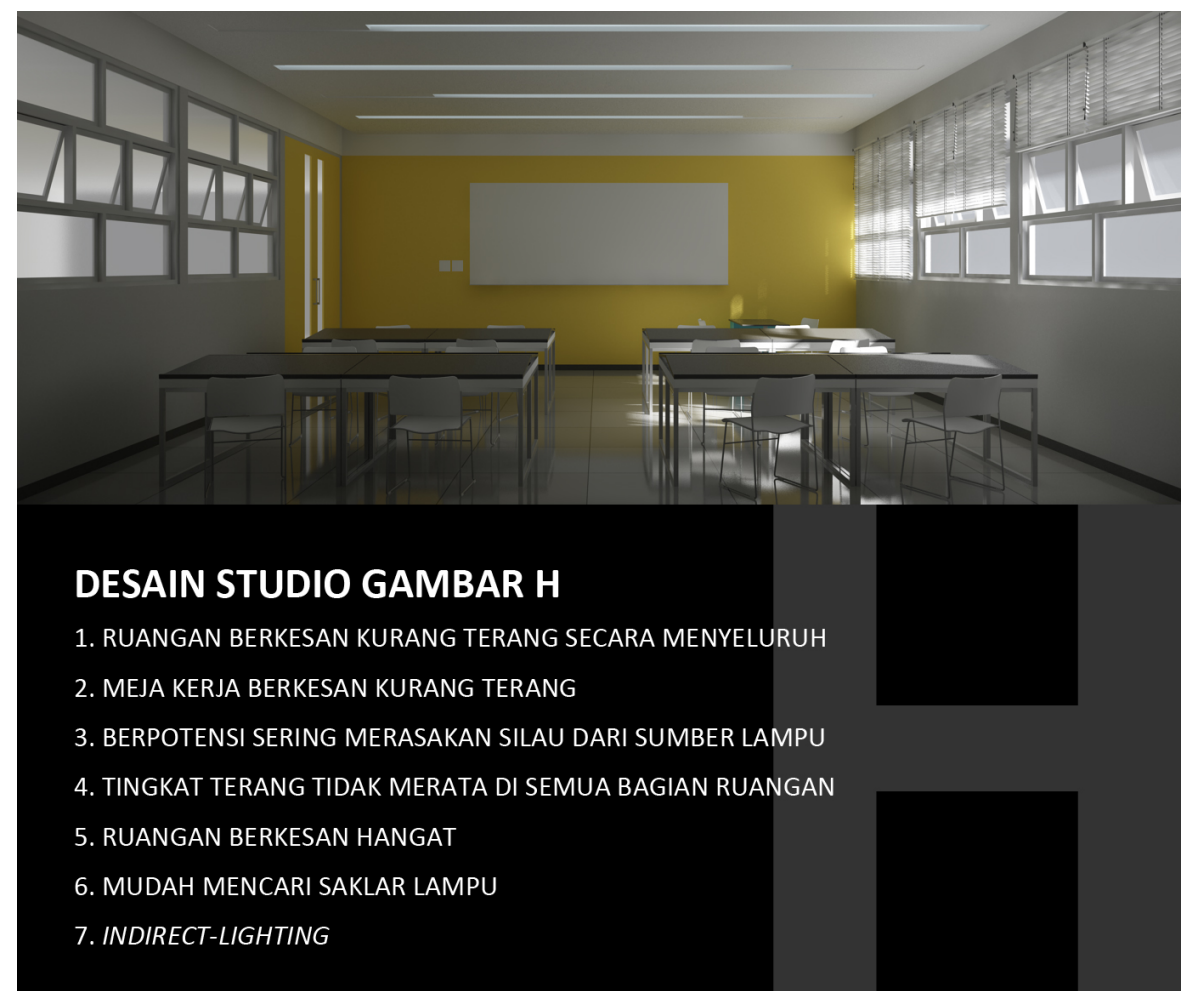

Gambar 8. Visualisasi pencahayaan studio gambar ideal - profil H, yang ditampilkan tercetak kepada responden 


\section{Pengumpulan dan Pengolahan Data}

Kedelapan profil dicetak pada kertas ukuran A2, lalu semuanya ditampilkan bersamaan di depan kelas agar responden mahasiswa dapat mengamati dengan jelas, baik tampilan gambar maupun keterangan di bawahnya. Karena terdapat empat tingkat studio desain (tingkat dua hingga lima), maka pengambilan data dilakukan bergilir sesuai jadwal studio yang tengah berlangsung pada semester yang bersangkutan.

Tiap responden mengamati kedelapan profil tadi agar mampu membandingkan cirinya secara cermat dan kemudian mengurutkan delapan profil mulai dari yang paling diminati hingga paling tidak diminati menurut persepsinya masing-masing.

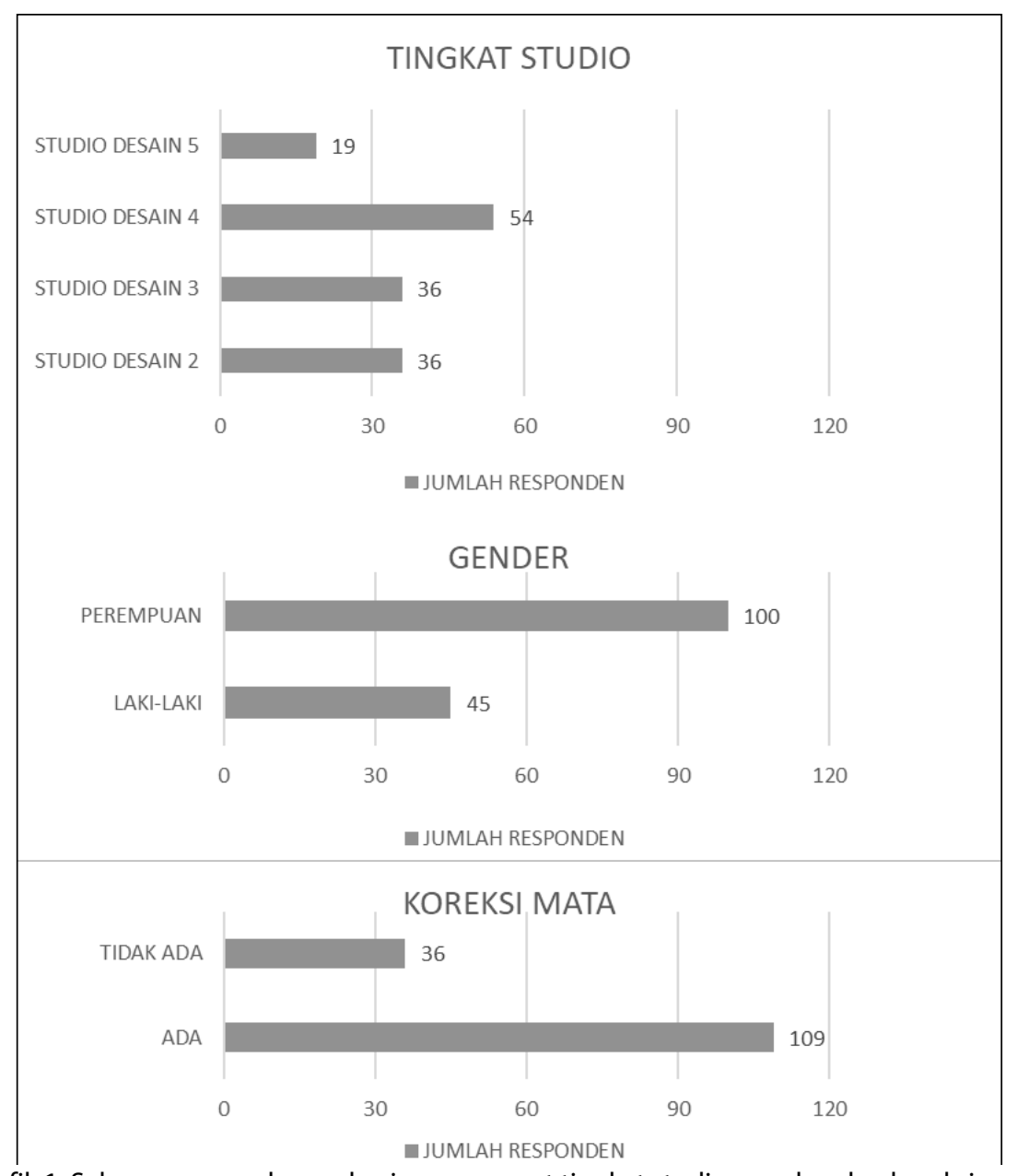

Grafik 1. Sebaran responden mahasiswa menurut tingkat studio, gender, dan koreksi mata

\section{PEMBAHASAN}




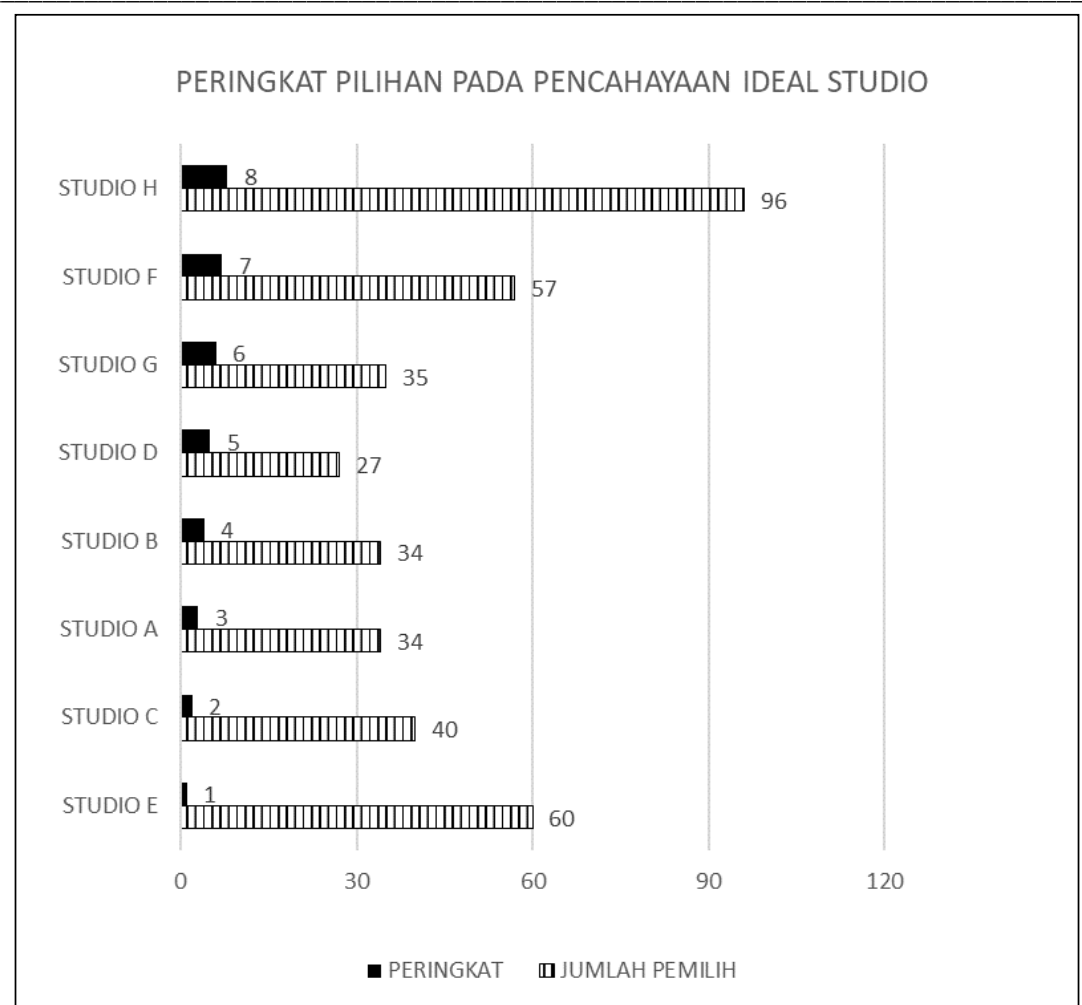

Grafik 2. Peringkat setiap profil pencahayaan studio hasil pilihan responden (1=paling diminati, $8=$ paling tidak diminati)

Dari kedelapan profil menurut peringkatnya terlihat adanya pergeseran preferensi dari total 145 responden. Pemilih terbanyak mulai dari profil E (pertama=41.4\%) yang paling diminati karena memiliki ciri-ciri atribut yang dinilai positif, lalu secara berurutan C (27.6\%), A (23.4\%), B (23.4\%), terus menurun hingga D (18.6\%), lalu kembali naik jumlah pemilihnya pada G (24.1\%), F (39.3\%), hingga puncaknya pada profil H (66.2\%) namun dengan ciri-ciri atribut yang dinilai paling tidak diminati. Perbedaan jumlah pemilih antara profil $\mathrm{E}$ dan profil $\mathrm{H}$ menunjukkan ketidakkonsistenan karena banyaknya ciri-ciri positif pada atribut dalam profil E tidak serta merta dinilai seimbang dengan jumlah ciri-ciri negatif pada atribut dalam profil H. Profil H dinilai memiliki preferensi terrendah oleh pemilih terbanyak (96 responden), dan sebaliknya profil E walaupun dinilai memiliki preferensi tertinggi namun dengan jumlah pemilih yang lebih sedikit (60 responden) daripada profil $\mathrm{H}$. Profil $\mathrm{H}$ memiliki atribut dengan kecenderungan gangguan lebih banyak dinilai lebih mudah dikonfirmasikan secara kentara oleh responden (melalui penggunaan kata kurang). 


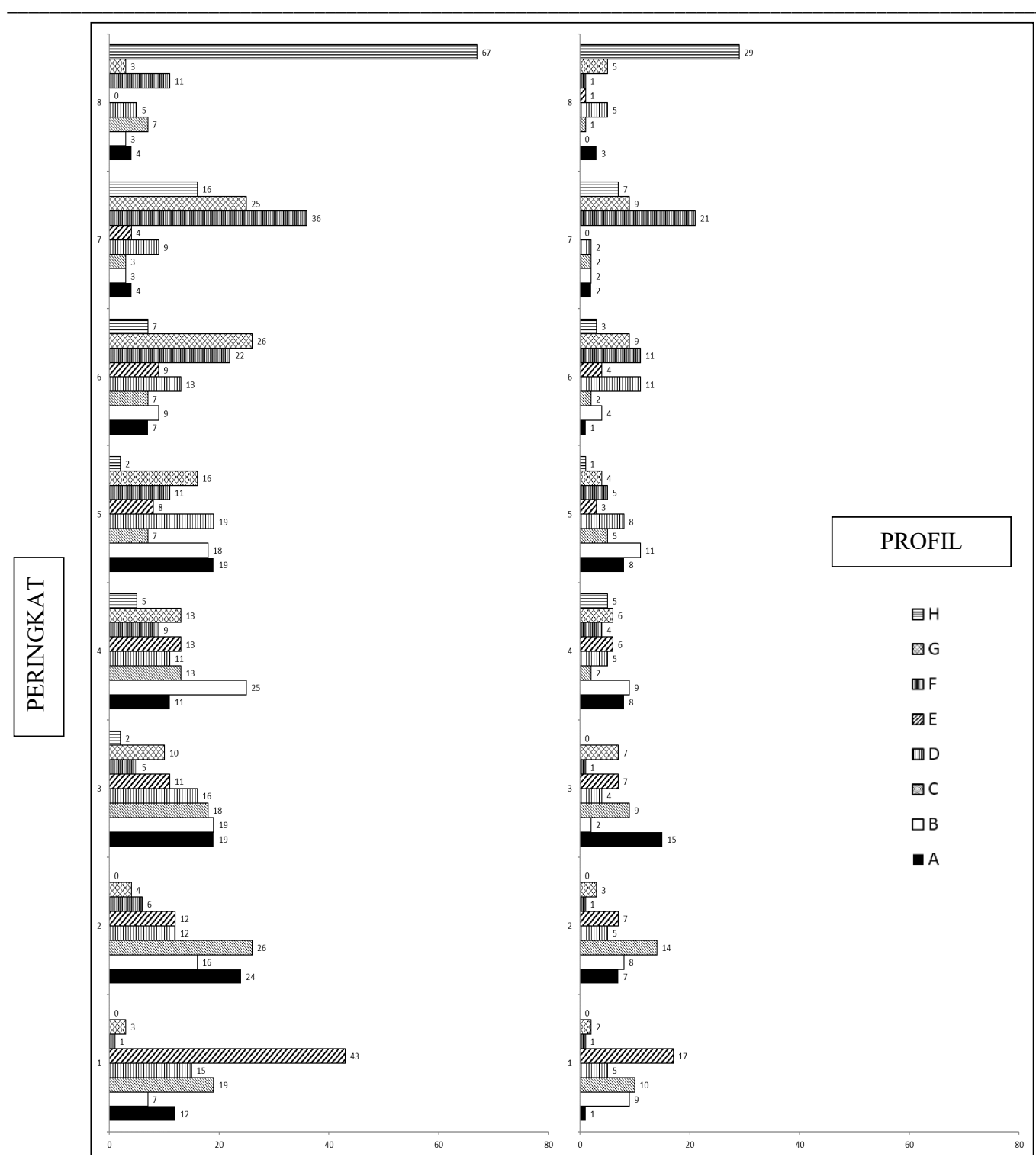

Grafik 3. J JUMLAH PEMIILIH PEREMPUAN = dari yang paling diminati (1) hingga yang paling tidak diminati (8) menurut kelompok gender.

Kelompok laki-laki mengurutkan profil E sebagai yang paling diminati, diikuti C, A, B, $B, D, F$, dan $H$. Sedangkan perempuan paling meminati profil E, lalu $C, B, B, D, G, F$, dan $\mathrm{H}$. Walaupun jumlah pemilih perempuan lebih banyak daripada laki-laki secara kentara, namun nampak kemiripan urutan pilihan secara agregat dari kedua grafik tersebut, artinya gender tidak berdampak kentara pada preferensi pencahayaan secara agregat. 


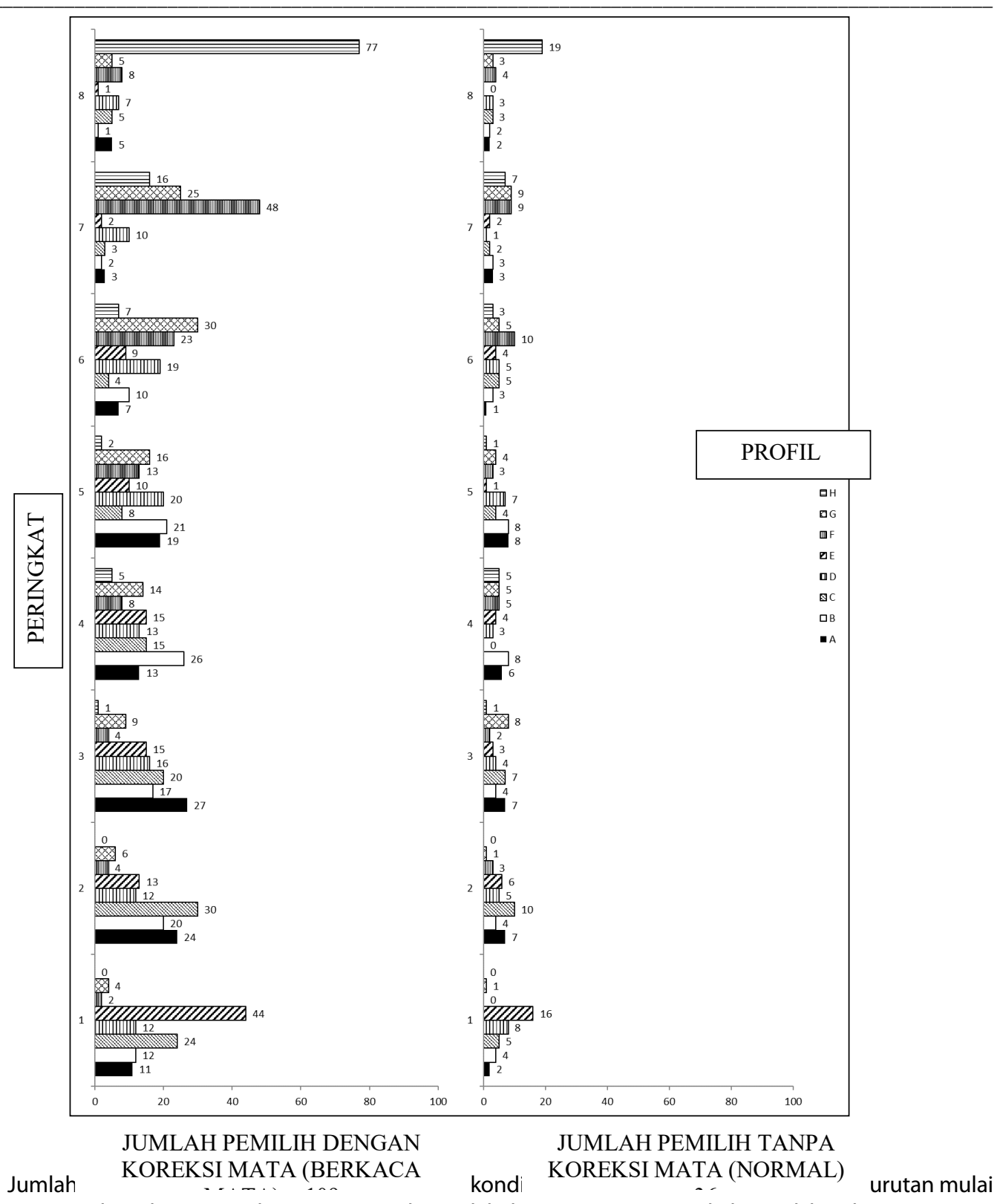

Grafik 4. Jumlah KOREKSI MATA (BERKACA dari yang paling diminati (1) hingga yang paling tidak diminati (8) menurut kelompok koreksi mata

Kelompok dengan koreksi mata mengurutkan profil E sebagai yang paling diminati, diikuti C, A, B, B, G, E, dan terakhir H. Kelompok tanpa koreksi mata mengurutkan profil E, diikuti $C, G, B, B, F, F$, dan terakhir $H$. Karena jumlah pemilih dengan koreksi mata jauh lebih banyak daripada pemilih tanpa koreksi mata secara kentara, maka perbedaan pilihan antar keduanya menjadikan tidak kentara secara agregat.

Tabel 2. Uraian atribut dari kedelapan profil pencahayaan studio gambar $(1=$ paling diminati, $8=$ paling tidak diminati) 


\begin{tabular}{llllllll}
\hline \hline & & & & & & & \\
& & & & & & \\
\hline
\end{tabular}

_ Tabel 3. Uraian urutan tingkat kepentingan atribut secara menyeluruh dari kedelapan profil dari tabel 2

\begin{tabular}{|c|c|c|c|c|c|c|c|c|}
\hline 岕导 & 玄怘 & 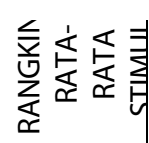 & 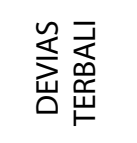 & 崖食 & 崖吉 & 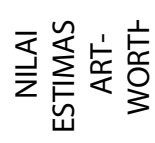 & 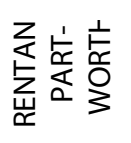 & 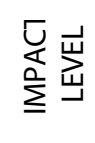 \\
\hline \multicolumn{9}{|c|}{1 TINGKAT TERANG SECARA UMUM } \\
\hline TERANG & $2 / 3 / 4 / 5$ & $14 / 4=3.5$ & $\begin{array}{c}3.5-4.5=- \\
1\end{array}$ & 1 & $-1 \times 1.34=-1.34$ & -1.16 & \multirow{2}{*}{2.32} & $\begin{array}{l}2.32 / 1 \\
2.74=\end{array}$ \\
\hline REDUP & $1 / 6 / 7 / 8$ & $22 / 4=5.5$ & $\begin{array}{c}5.5- \\
4.5=1\end{array}$ & 1 & $1 \times 1.34=1.34$ & 1.16 & & $\begin{array}{c}18.2 \% \\
(2)\end{array}$ \\
\hline \multicolumn{9}{|c|}{2 TINGKAT TERANG DI ATAS MEJA KERJA } \\
\hline TERANG & $1 / 3 / 4 / 7$ & $\begin{array}{c}15 / 4=3.7 \\
5\end{array}$ & $\begin{array}{c}3.75- \\
4.5=- \\
0.75\end{array}$ & 0.56 & $\begin{array}{c}-0.56 \times 1.34=- \\
0.75\end{array}$ & -0.87 & \multirow{2}{*}{1.74} & $\begin{array}{l}1.74 / 1 \\
2.74=\end{array}$ \\
\hline REDUP & $2 / 5 / 6 / 8$ & $\begin{array}{c}21 / 4=5.2 \\
5 \\
\end{array}$ & $\begin{array}{c}5.25- \\
4.5=0.75\end{array}$ & 0.56 & $0.56 \times 1.34=0.75$ & 0.87 & & $\begin{array}{c}13.7 \% \\
(3)\end{array}$ \\
\hline \multicolumn{9}{|c|}{3 SILAU } \\
\hline SERING & $3 / 4 / 6 / 8$ & $\begin{array}{c}21 / 4=5.2 \\
5\end{array}$ & $\begin{array}{c}5.25- \\
4.5=0.75\end{array}$ & 0.56 & $0.56 \times 1.34=0.75$ & 0.87 & \multirow[b]{2}{*}{1.74} & $1.74 / 1$ \\
\hline JARANG & $1 / 2 / 5 / 7$ & $\begin{array}{c}15 / 4=3.7 \\
5\end{array}$ & $\begin{array}{c}3.75- \\
4.5=- \\
0.75\end{array}$ & 0.56 & $\begin{array}{c}-0.56 \times 1.34=- \\
0.75\end{array}$ & -0.87 & & $\begin{array}{c}2.74= \\
13.7 \% \\
(4)\end{array}$ \\
\hline \multicolumn{9}{|c|}{4 DISTRIBUSI PENCAHAYAAN } \\
\hline RATA & $1 / 2 / 3 / 6$ & $12 / 4=3$ & $\begin{array}{c}3-4.5=- \\
1.5\end{array}$ & 2.25 & $\begin{array}{c}-2.25 \times 1.34=- \\
3.02\end{array}$ & -1.74 & \multirow{2}{*}{3.48} & $\begin{array}{l}3.48 / 1 \\
2.74=\end{array}$ \\
\hline (-) RATA & $4 / 5 / 7 / 8$ & $24 / 4=6$ & $\begin{array}{c}6- \\
4.5=1.5\end{array}$ & 2.25 & $2.25 \times 1.34=3.02$ & 1.74 & & $\begin{array}{c}27.3 \% \\
(1)\end{array}$ \\
\hline \multicolumn{9}{|c|}{5 TEMPERATUR WARNA } \\
\hline HANGAT & $2 / 3 / 7 / 8$ & $20 / 4=5$ & $\begin{array}{c}5- \\
4.5=0.5 \\
\end{array}$ & 0.25 & $0.25 \times 1.34=0.34$ & 0.58 & \multirow{2}{*}{1.16} & $\begin{array}{l}1.16 / 1 \\
2.74=\end{array}$ \\
\hline SEJUK & $1 / 4 / 5 / 6$ & $16 / 4=4$ & $\begin{array}{c}4-4.5=- \\
0.5\end{array}$ & 0.25 & $\begin{array}{c}-0.25 \times 1.34=- \\
0.34\end{array}$ & -0.58 & & $\begin{array}{c}9.1 \% \\
(6)\end{array}$ \\
\hline \multicolumn{9}{|c|}{6 KEMUDAHAN KONTROL } \\
\hline MUDAH & $1 / 3 / 5 / 8$ & $\begin{array}{c}17 / 4=4.2 \\
5\end{array}$ & $\begin{array}{c}4.25- \\
4.5=- \\
0.25\end{array}$ & 0.06 & $\begin{array}{c}-0.06 \times 1.34=- \\
0.08\end{array}$ & -0.28 & \multirow{2}{*}{0.56} & $\begin{array}{l}0.56 / 1 \\
2.74=\end{array}$ \\
\hline SULIT & $2 / 4 / 6 / 7$ & $\begin{array}{c}19 / 4=4.7 \\
5\end{array}$ & $\begin{array}{c}4.75- \\
4.5=0.25\end{array}$ & 0.06 & $0.06 \times 1.34=0.08$ & 0.28 & & $\begin{array}{c}4.4 \% \\
\text { (7) }\end{array}$ \\
\hline \multicolumn{9}{|c|}{7 TIPE PENYINARAN } \\
\hline DIRECT & $3 / 5 / 6 / 7$ & $\begin{array}{c}21 / 4=5.2 \\
5\end{array}$ & $\begin{array}{c}5.25- \\
4.5=0.75\end{array}$ & 0.56 & $0.56 \times 1.34=0.75$ & -0.87 & \multirow[b]{2}{*}{1.74} & $1.74 / 1$ \\
\hline INDIRECT & $1 / 2 / 4 / 8$ & $\begin{array}{c}15 / 4=3.7 \\
5\end{array}$ & $\begin{array}{c}3.75- \\
4.5=- \\
0.75\end{array}$ & 0.56 & $\begin{array}{c}-0.56 \times 1.34=- \\
0.75\end{array}$ & 0.87 & & $\begin{array}{c}2.74= \\
13.7 \% \\
(5)\end{array}$ \\
\hline
\end{tabular}




\begin{tabular}{c|c|c|c|c|c|c}
\hline & & & $\mathbf{1 0 . 4 8}$ & & $\mathbf{1 2 . 7 4}$ & $\mathbf{1 3 . 7}$ \\
$\%$
\end{tabular}

Hasil perhitungan nilai rentang part-worth menurut ranking kedelapan profil menghasilkan urutan (dari tertinggi hingga terendah) tingkat kepentingan dari ketujuh atribut sebagai berikut: (1) distribusi pencahayaan 27.3\%, (2) tingkat terang secara menyeluruh 18.2\%, (3) tingkat terang pada meja kerja 13.7\%, (4) potensi silau dari sumber lampu 13.7\%, (5) tipe penyinaran 13.7\%, (6) temperatur warna lampu 9.1\%, dan terakhir (7) kemudahan kontrol 4.4\%.

\section{PENUTUP}

Tiga atribut dengan persentase terbesar secara agregat dari pencahayaan studio gambar menurut preferensi responden adalah: (1) distribusi pencahayaan, hal ini dapat dipahami mengingat studio gambar digunakan bersama-sama, sehingga tentunya memerlukan tingkat terang yang merata di seluruh bagian ruangan agar mampu mendukung pergantian konfigurasi meja kerja saat diperlukan. Selanjutnya, tingkat terang (2) studio secara menyeluruh hendak menunjukkan bahwa ketika studio gambar memiliki tingkat terang yang tepat tentunya sangat mendukung kinerja melihat tanpa beban berlebih sehingga stamina bekerja untuk waktu yang panjang terjaga. Tingkat terang di atas meja kerja (3) dipentingkan untuk mendukung fleksibilitas pengaturan tingkat terang secara individual mengingat adanya perbedaan preferensi antar pengguna terutama saat ada gangguan stabilitas atau kemerataan pencahayaan dalam studio.

Keempat atribut berikutnya secara berurutan, yaitu (4) potensi silau menunjukkan kemungkinan gangguan silau pada lokasi meja kerja, (5) tipe penyinaran langsung atau tidak langsung oleh sumber cahaya dalam studio, (6) pewarnaan sejuk dari sumber cahaya, dan terakhir (7) kemudahan kontrol untuk mengatur preferensi pengkondisian pencahayaan studio.

Ketiga atribut terbesar (primer) tadi menunjukkan unsur pencahayaan yang dinilai responden paling berpengaruh pada kinerja pengguna untuk menggambar, sedangkan sisanya dianggap sebagai nilai tambah (sekunder) yang baru berpengaruh hanya jika preferensi pada ketiga atribut pertama tadi terpenuhi. 
Dengan demikian, komposisi tingkat prioritas atribut berikut urutannya di atas menjadi ciri khas pencahayaan studio gambar yang ideal (E) menurut preferensi pengguna secara agregat.

\section{Keterbatasan Penelitian}

Jumlah atribut dan jumlah level dalam penelitian ini (7 atribut dengan 2 level) yang diminimalkan dengan teknik orthogonal menyajikan jumlah pilihan yang terbatas, begitu pula dengan keterbatasan waktu responden karena pengambilan data dilakukan di tengah jam studio. Penelitian ini bergantung pada preferensi pengguna yang populasinya adalah mahasiswa aktif studio tingkat dua hingga lima pada semester yang bersangkutan, sehingga preferensinya cenderung dapat berubah di waktu yang berbeda bergantung pada interpretasi pengalaman subjektif responden mengenai kondisi pencahayan studio.

\section{Penelitian Lanjutan}

Potensi penelitian di masa depan adalah melakukan proses serupa sebagai konfirmasi atas temuan saat ini dengan populasi responden yang lebih besar sehingga memperoleh pemahaman baru dan mendalam mengenai preferensi pengguna pada pencahayaan studio di waktu yang berbeda. 


\section{DAFTAR PUSTAKA}

Boyce, Peter R., Wilkins, A. (2018). Visual Discomfort Indoors. Lighting Research Technology vol.50 p.98-114.

Cheung, H.D., Chung, T.M. (2008). A Study on Subjective Preference to Daylit Residential Indoor Environment Using Conjoint Analysis. ScienceDirect: Building and Environment 43 p.2101-2111.

Dora, Purnama Esa. (2012). Hubungan Arah Pencahayaan Buatan Terhadap Kenyamanan dan Efisiensi Kerja. Seminar Nasional Dies Jurusan Arsitektur Universitas Kristen Petra.

Hathaway, Warren E. et al. (1992). A Study Into the Effects of Light on Children of Elementary School Age - A Case of Daylight Robbery. IRC Internal Report no. 659 p.11-29.

IESNA Lighting Handbook Vol.9.

Innes, Malcolm. (2012). Lighting for Interior Design. Laurence King Publishing Ltd.

Samani, Sanaz. (2011). The Influence of Light on Student's Learning Performance in Learning Environments : A Knowledge Internalization Perspective. World Academy of Science, Engineering, and Technology 57p.540-547. 